\section{New NICE abortion care guidance: what does it mean for antibiotic use?}

The 2019 published National Institute for Health and Care Excellence abortion care guidance (NG140) recommends that antibiotic prophylaxis is offered to women who are having a surgical abortion and, when using doxycycline, a $100 \mathrm{mg}$ two times a day for 3 days should be considered. The rationale to the recommendation states 'a three day course because this may be as effective and adherence is likely to be better with a shorter outcome'. This is a shorter duration than that presented as part of the consultation. Originally, 'the committee agreed that 7 days of doxycycline should be considered as it would be sufficient to treat sexually transmitted infections (STIs), if present. Further, there was expert knowledge that there is no evidence of increased antimicrobial resistance (AMR) with 7 days, compared with 3 days, of treatment. This is also consistent with the UK national recommendations for treating chlamydia'. ${ }^{1}$

The evidence review concluded that 'Randomised controlled trial evidence showed there was no clinically important difference between the rate of adherence to antibiotics in the 3 day doxycycline antibiotic prophylaxis group and the 7 day doxycycline antibiotic prophylaxis group'. Additionally, the 'RCT evidence did not detect a clinically important difference in the rates of vomiting... No evidence was found for nausea'. Therefore, the rationale for reducing the recommendation to 3 days cannot be based on improved adherence or side-effect profile.

Only one randomised controlled trial, ${ }^{2}$ was identified using their search criteria to answer the question 'What is the optimal antibiotic prophylaxis regimen for women who are having a surgical termination of pregnancy?' The study concluded that 'Shortening oral doxycycline prophylaxis from 7 to 3 days had no adverse effect on the incidence of post-abortion infection'. Given that (1) $63 \%$ of women with chlamydia will develop pelvic inflammatory disease (PID) following surgical termination of pregnancy (TOP), ${ }^{3}$ (2) 7-day treatment is required to successfully treat chlamydia ${ }^{1}$ and (3) in the UK, chlamydia is common in women having an abortion $(5 \%-7.6 \%),{ }^{4}$ how can the conclusion of the expert review group be correct. We argue that it is because the panel failed to consider that the population studied by Litchenberg and Shott is not representative of the majority of women undergoing TOP in the UK. ${ }^{2}$ The authors state that STIs were uncommon in their population, women had a mean age 26.6 years (chlamydia is associated with age $<25$ years $)^{1}$, they had a low incidence of postabortion infection and they did not test for chlamydia as part of the study. ${ }^{2}$ As chlamydia was uncommon, we cannot be confident that this study would detect a difference in postabortion infection rates between the 3-day and 7-day course in women who are chlamydia positive. Therefore, it is inappropriate to generalise the findings of Litchenberg and Shott to women undergoing TOP in the UK today. ${ }^{2}$

The guideline also suggests using poorly defined criteria to identify women at risk of chlamydia '...unprotected sex and frequent change of and/or multiple sexual partners'. The criteria of unprotected sex will have been met by all women presenting for an abortion and in women undergoing TOP partner change is not a risk factor for chlamydia in women undergoing TOP. $^{4}$

We therefore recommend that: 'When using doxycycline for antibiotic prophylaxis in surgical abortion, oral doxycycline $100 \mathrm{mg}$ twice a day for 7 days is recommended. A 3 day course can be considered if the woman is undergoing a vacuum aspiration and chlamydia infection has been excluded using a nucleic acid amplification test'. Women should also be advised that if they develop symptoms suggestive of PID, they should seek medical care as early treatment reduces the risk of longterm sequelae such as infertility.

\section{Karla Blee $\odot$, ${ }^{1}$ Paddy J Horner ${ }^{2,3}$}

${ }^{1}$ Sexual Health Service, Betsi Cadwaladr University Health Board, Rhyl, UK

${ }^{2}$ Population Health Sciences, University of Bristol, Bristol, UK

${ }^{3}$ Unity Sexual Health, University Hospitals Bristol NHS Foundation Trust, Bristol, UK

Correspondence to Dr Karla Blee, Sexual Health Service, Betsi Cadwaladr University Health Board, Denbighshire, LL18 5UJ, UK; karla.blee@wales.nhs.uk
Funding The authors have not declared a specific grant for this research from any funding agency in the public, commercial or not-for-profit sectors.

Disclaimer The views expressed are those of the authors and not necessarily those of the NHS, the NIHR, the Department of Health or Public Health England.

Competing interests $\mathrm{PJH}$ was supported by the National Institute of Health Research Health Protection Research Unit in Evaluation of Interventions at the University of Bristol in partnership with Public Health England.

Patient and public involvement Patients and/or the public were not involved in the design, or conduct, or reporting, or dissemination plans of this research.

Patient consent for publication Not required.

Provenance and peer review Not commissioned; internally peer reviewed.

(c) Author(s) (or their employer(s)) 2021. No commercial re-use. See rights and permissions. Published by BMJ.

\section{Check for updates}

Published Online First 16 April 2020

BMJ Sex Reprod Health 2021;47:69.

doi:10.1136/bmjsrh-2020-200627

ORCID iD

Karla Blee http://orcid.org/0000-00023745-8491

\section{REFERENCES}

1 Nwokolo NC, Dragovic B, Patel S, et al. 2015 UK national guideline for the management of infection with Chlamydia trachomatis. Int J STD AIDS 2016;27:251-67.

2 Lichtenberg ES, Shott S. A randomized clinical trial of prophylaxis for vacuum abortion: 3 versus 7 days of doxycycline. Obstet Gynecol 2003;101:726-31.

3 Blackwell AL, Thomas PD, Wareham $\mathrm{K}$, et al. Health gains from screening for infection of the lower genital tract in women attending for termination of pregnancy. Lancet 1993;342:206-10.

4 Mallinson H, Hopwood J, Skidmore S, et al. Provision of Chlamydia testing in a nationwide service offering termination of pregnancy: with data capture to monitor prevalence of infection. Sex Transm Infect 2002;78:416-21.

5 Junghans C, Warren K, Coley D, et al. The prevalence of chlamydia in pregnant women compared with non-pregnant women in a busy sexual health clinic in the UK: Making the case for systematic chlamydia screening in pregnancy?. Sex Transm Infect 2016;92:A89-90. 